\title{
Mathematical modelling to centre low tidal volumes following acute lung injury: A study with biologically variable ventilation M Ruth Graham ${ }^{\dagger 1}$, Craig J Haberman ${ }^{1}$, John F Brewster ${ }^{2}$, Linda G Girling1, Bruce M McManus ${ }^{3}$ and W Alan C Mutch*†1
}

Address: ${ }^{1}$ Department of Anesthesia, University of Manitoba, Winnipeg, Manitoba, Canada, ${ }^{2}$ Institute of Industrial Mathematical Sciences, University of Manitoba, Winnipeg, Manitoba, Canada and ${ }^{3}$ Department of Pathology and Laboratory Medicine, James Hogg iCAPTURE Centre for Cardiovascular and Pulmonary Research, University of British Columbia, Vancouver, British Columbia, Canada

Email: M Ruth Graham - mrgraha@cc.umanitoba.ca; Craig J Haberman - chabs@mts.net; John F Brewster - john_brewster@umanitoba.ca; Linda G Girling - girling1@cc.umanitoba.ca; Bruce M McManus - bmcmanus@mrl.ubc.ca; W Alan C Mutch* - amutch@cc.umanitoba.ca

* Corresponding author †Equal contributors

Published: 28 June 2005

Respiratory Research 2005, 6:64 doi:10.1 186/1465-992I-6-64

This article is available from: http://respiratory-research.com/content/6/I/64

(c) 2005 Graham et al; licensee BioMed Central Ltd.

This is an Open Access article distributed under the terms of the Creative Commons Attribution License (http://creativecommons.org/licenses/by/2.0), which permits unrestricted use, distribution, and reproduction in any medium, provided the original work is properly cited.

\begin{abstract}
Background: With biologically variable ventilation [BVV - using a computer-controller to add breath-tobreath variability to respiratory frequency $(f)$ and tidal volume $\left(V_{T}\right)$ ] gas exchange and respiratory mechanics were compared using the ARDSNet low $V_{T}$ algorithm (Control) versus an approach using mathematical modelling to individually optimise $V_{T}$ at the point of maximal compliance change on the convex portion of the inspiratory pressure-volume $(P-V)$ curve (Experimental).
\end{abstract}

Methods: Pigs $(n=22)$ received pentothal/midazolam anaesthesia, oleic acid lung injury, then inspiratory P-V curve fitting to the four-parameter logistic Venegas equation $F(P)=a+b\left[1+\mathrm{e}^{-(P-c) / d}\right]^{-1}$ where: $a=$ volume at lower asymptote, $b=$ the vital capacity or the total change in volume between the lower and upper asymptotes, $c=$ pressure at the inflection point and $d=$ index related to linear compliance. Both groups received BVV with gas exchange and respiratory mechanics measured hourly for $5 \mathrm{hrs}$. Postmortem bronchoalveolar fluid was analysed for interleukin-8 (IL-8).

Results: All $P-V$ curves fit the Venegas equation $\left(R^{2}>0.995\right)$. Control $V_{T}$ averaged $7.4 \pm 0.4 \mathrm{~mL} / \mathrm{kg}$ as compared to Experimental $9.5 \pm 1.6 \mathrm{~mL} / \mathrm{kg}$ (range $6.6-10.8 \mathrm{~mL} / \mathrm{kg} ; \mathrm{p}<0.05$ ). Variable $\mathrm{V}_{T} \mathrm{~s}$ were within the convex portion of the P-V curve. In such circumstances, Jensen's inequality states "if $F(P)$ is a convex function defined on an interval $(r, s)$, and if $P$ is a random variable taking values in $(r, s)$, then the average or expected value $(E)$ of $F(P) ; E(F(P))>F(E(P))$." In both groups the inequality applied, since $F(P)$ defines volume in the Venegas equation and $(P)$ pressure and the range of $V_{T} S$ varied within the convex interval for individual P-V curves. Over 5 hrs, there were no significant differences between groups in minute ventilation, airway pressure, blood gases, haemodynamics, respiratory compliance or IL-8 concentrations.

Conclusion: No difference between groups is a consequence of BVV occurring on the convex interval for individualised Venegas P-V curves in all experiments irrespective of group. Jensen's inequality provides theoretical proof of why a variable ventilatory approach is advantageous under these circumstances. When using BVV, with $V_{T}$ centred by $V$ enegas $P-V$ curve analysis at the point of maximal compliance change, some leeway in low $V_{T}$ settings beyond $A R D S N$ et protocols may be possible in acute lung injury. This study also shows that in this model, the standard ARDSNet algorithm assures ventilation occurs on the convex portion of the P-V curve. 


\section{Background}

Mathematical modelling has contributed to our understanding of lung mechanics and helped direct therapy in patients with acute respiratory distress syndrome (ARDS). Hickling [1,2] generated sigmoidal pressure-volume (P-V) curves based on a model where airway opening could occur over the entire inflation limb. Venegas and colleagues [3,4] devised a four-parameter logistic model to fit $\mathrm{P}-\mathrm{V}$ inflation curves in patients with ARDS. In most instances, the Venegas equation fits static P-V data with great precision. Such modelling indicates that ventilation is limited to the convex portion of the static inflation curve when the low tidal volume $\left(\mathrm{V}_{\mathrm{T}}\right)$ ARDSNet algorithm is utilised [5].

We have recently shown mathematically that if ventilation is occurring on the convex portion of the P-V curve, there is an advantage to adding noise to the end-inspiratory pressure signal [6,7]. Using a newer mode of mechanical ventilation - termed biologically variable ventilation (BVV) - noise is added to the end-inspiratory pressure signal [8]. As configured this noise can be shown to have fractal or $1 / \mathrm{f}$ characteristics [9]. This computer-controlled ventilator simulates breath-to-breath variation in respiratory frequency $(f)$ and $\mathrm{V}_{\mathrm{T}}$ that characterises normal spontaneous ventilation. The added noise results in greater mean $\mathrm{V}_{\mathrm{T}}$ over time at the same mean driving pressure. This, perhaps counter-intuitive finding, can be deduced by applying Jensen's inequality - a simple probabilistic proof $[7,10]$. Jensen's inequality states that the average or expected value of a convex function over a random variable is greater than the value of that function at the average of the random variable. In mathematical terms in the notation of the Venegas equation, "if $F(P)=V$ is a convex function defined on an interval $(r, s)$, and if pressure $(P)$ is a random variable taking values in $(r, s)$, then the expected value $(E)$ at $F(P) ; E(F(P))>F$ at the expected value of $P$; $F(E(P))$." Such conditions are met with BVV since noisy ventilation provides a series of individualised observations of pressure $(P)$, that are transformed to volume $F(P)$ as determined by Venegas curve fitting.

Jensen's inequality, thus, provides us with an important tool to determine if noise will be beneficial or not. Indirectly it also indicates where the noise will be most beneficial - when ventilation is centred at the point where the convexity is most pronounced - the point where the second derivative of the convex interval of the function is maximised. For the Venegas equation this occurs at the point of maximal compliance change: when $P=c-1.317 d$ or when $V=a+0.211 b[3,6]$.

Based on the above information, we designed an experiment to compare the presumed "mathematically optimised" point about which to centre noise (Experimental) to an approach using the ARDSNet algorithm (Control). We presumed that the ARDSNet algorithm would also result in ventilation on the convex portion of the P-V curve, but advanced the hypothesis that by mathematical modelling individual P-V curves, we could find an optimised strategy for BVV that would result in discernable improvements over an approach using the ARDSNet algorithm alone with BVV. A porcine model of lung injury with oleic acid was studied. We compared gas exchange, respiratory mechanics and a single marker of inflammation over 5 hrs for the two approaches.

\section{Methods}

\section{Experimental preparation}

Twenty-eight pigs were studied following the Canadian Council on Animal Care Guidelines. The experimental preparation has been described previously [11]. Briefly, animals were ventilated initially with an Esprit ${ }^{\circledR}$ ventilator (Respironics Inc., Carlsbad, CA) using $\mathrm{V}_{\mathrm{T}}=12 \mathrm{~mL} / \mathrm{kg}, f=$ 20 bpm, $\mathrm{F}_{\mathrm{I}} \mathrm{O}_{2} 0.5$ and PEEP $4 \mathrm{~cm} \mathrm{H} \mathrm{H}_{2} \mathrm{O}$ during surgical placement of monitoring cannulae. Anaesthesia was maintained with an intravenous loading dose and continuous infusion of sodium thiopental/midazolam at 16/0.1 $\mathrm{mg} / \mathrm{kg} / \mathrm{hr}$ and paralysis with doxacurium infusion (1.5 $2 \mathrm{mg} / \mathrm{kg} / \mathrm{hr}$ ).

\section{Oleic Acid Lung Injury}

Baseline measurements were obtained and an infusion of oleic acid (BDH, Toronto, ON) started at $0.2 \mathrm{~mL} / \mathrm{kg} / \mathrm{hr}$ through a catheter, placed in the inferior vena cava, above the level of the diaphragm. The oleic acid infusion was continued until $\mathrm{PaO}_{2}$ decreased to $<80 \mathrm{~mm} \mathrm{Hg}$ for two consecutive measurements, $5 \mathrm{~min}$ apart (20 - $45 \mathrm{~min}$ of infusion), and the volume noted. An additional $4 \mathrm{~cm} \mathrm{H}_{2} \mathrm{O}$ PEEP was then added (to a total of $8 \mathrm{~cm} \mathrm{H}_{2} \mathrm{O}$ ) and arterial blood gases were obtained at 10 and $15 \mathrm{~min}$. The criterion for study inclusion was a $\mathrm{PaO}_{2}>80 \mathrm{mmHg}$ and $<200$ mmHg on $8 \mathrm{~cm} \mathrm{H}_{2} \mathrm{O}$ of PEEP. This was not considered to represent steady-state but was used as an index of adequate lung injury $\left(\mathrm{PaO}_{2}<80 \mathrm{~mm} \mathrm{Hg}\right)$ as well as evidence for lung recruitability $\left(80<\mathrm{PaO}_{2}<200 \mathrm{~mm} \mathrm{Hg}\right)$. A continuous infusion of dopamine $(5-10 \mu \mathrm{g} / \mathrm{kg} / \mathrm{min})$ was started with oleic acid infusion to maintain mean arterial pressure $>50 \mathrm{mmHg}$.

\section{Static Pressure-Volume Curves}

Pressure-volume curves were generated for each animal after established lung injury. $\mathrm{F}_{\mathrm{I}} \mathrm{O}_{2}$ was increased to 1.0, PEEP decreased to $0 \mathrm{~cm} \mathrm{H}_{2} \mathrm{O}$, and $f$ was decreased to 10 bpm with an inspiratory hold of $2 \mathrm{sec}$, at a square-wave flow rate of $30 \mathrm{~L} / \mathrm{min}$. A sequence of $\mathrm{V}_{\mathrm{T}}$ s from 50 to 1200 $\mathrm{mL}$ was delivered and plateau pressure measured $1 \mathrm{sec}$ after end inspiration. Preliminary trials yielded similar curves with $\mathrm{V}_{\mathrm{T}}$ delivered in either random or ascending sequences, so the latter was used. The resulting P-V curve 


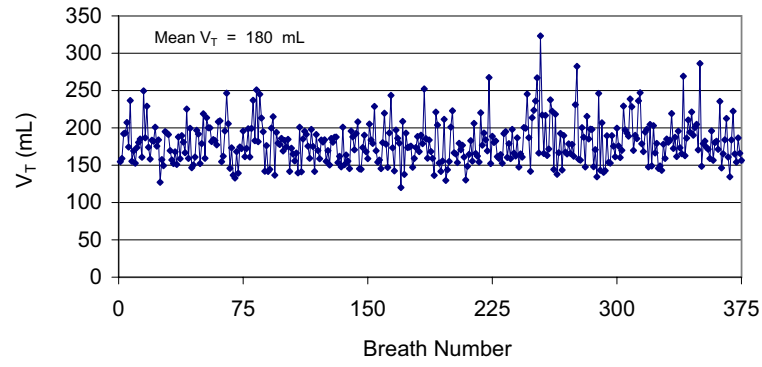

Figure I

Delivery of Variable Tidal Volume. The complete data set of delivered tidal volume $\left(\mathrm{V}_{\mathrm{T}}\right)$ using $\mathrm{BV}$ in one animal. There were 376 breaths in the file. Mean $V_{T}$ was set at 180 $\mathrm{mL}$ in this example.

was analysed using a non-linear regression curve-fitting program (NCSS 97) that performs a series of iterations. We used the four-parameter logistic equation derived by Venegas et al. [3] to curve fit:

$F(P)=a+b\left[1+e^{-(P-c) / d}\right]^{-1}$

where: $a$ = volume at the lower asymptote, $b=$ the vital capacity or the total change in volume between the lower and upper asymptotes, $c=$ pressure at the true inflection point and $d=$ an index of the linear compliance for the curve. The maximal rate of change in compliance is the point where the second derivative is maximal: found at the point $P=c-1.317 d$ or $V=a+0.211 b$.

\section{Ventilation Protocol}

The animals were then randomised to BVV centred at $\mathrm{V}_{\mathrm{T}}$ of $7 \mathrm{~mL} / \mathrm{kg}$, (Control) or at the $\mathrm{V}_{\mathrm{T}}$ corresponding to the maximal rate of change in compliance from the P-V curve (Experimental) for 5 hrs. We used the computer-controller and software to generate the variable ventilatory pattern as previously described [11]. A representative variability file is shown in Figure $1 . \mathrm{F}_{\mathrm{I}} \mathrm{O}_{2}$ was set at 0.5 with PEEP $8 \mathrm{~cm} \mathrm{H}_{2} \mathrm{O}$. Respiratory frequency was initially set at $25 \mathrm{bpm}$. We followed the ARDSNet algorithm for $\mathrm{pH}$ control - the base $\mathrm{V}_{\mathrm{T}}$ of $7 \mathrm{~mL} / \mathrm{kg}$ in the Control group is greater than the $6 \mathrm{~mL} / \mathrm{kg}$ seen in human studies due, in part, to dead space associated with in-line breathing circuit measurement devices. If $\mathrm{pH}$ fell below 7.2, $f$ was incrementally increased by 5 bpm up to a maximum of 35 $\mathrm{bpm}$. If respiratory acidosis persisted, $\mathrm{V}_{\mathrm{T}}$ could be adjusted in increments of $0.5 \mathrm{~mL} / \mathrm{kg}$ to a maximum of $8 \mathrm{~mL} / \mathrm{kg}$. Haemodynamics, airway pressures, arterial and venous blood gases and static compliance were determined at baseline, after oleic acid, after generation of the P-V curve and then hourly for 5 hrs.

\section{Bronchoalveolar Fluid Cytokines and Wet/Dry Weight Ratios}

Bronchoalveolar fluid aspirates were obtained immediately post-mortem. These samples were frozen and kept at $-80^{\circ} \mathrm{C}$ until analysis. Analyses were made in duplicate to determine the concentrations of IL- 8 by sandwich ELISA. A species-specific assay was used (IL-8, Medicorp KSC0082, detection limit $10 \mathrm{pg} / \mathrm{mL}$ ). ELISA plates were incubated at $4{ }^{\circ} \mathrm{C}$ overnight with $50 \mu \mathrm{L}$ per well with 1 $\mathrm{mg} / \mathrm{mL}$ of anti-IL-8. Plates were washed 4 times and nonspecific binding was blocked with $200 \mu \mathrm{L}$ of phosphatebuffered saline (PBS) with $2 \%$ bovine serum albumin (BSA) per well for 90 min. Diluted cell-free supernatants $(50 \mu \mathrm{L})$ were added and incubated for $3 \mathrm{hr}$. A volume of $50 \mu \mathrm{L}(1 \mathrm{mg} / \mathrm{mL})$ of biotinylated antibody was added and incubated for $60 \mathrm{~min}$. Subsequently, avidin peroxidase conjugate was added (Bio-Rad Laboratories) followed by chromogen substrate (ortho-phenylenediamine [OPD], Dako). Plates were read at $490 \mathrm{~nm}$ using an ELISA reader (Rainbow Reader, SLT Lab Instruments). The analysis of aspirates was done in a blinded fashion at the James Hogg iCAPTURE Centre for Cardiovascular and Pulmonary Research, University of British Columbia.

\section{Statistical Analysis}

Data were analysed by repeated measures analysis of variance (ANOVA) as previously described. The group $\times$ time interactions were considered significant when $\mathrm{p}<0.05$. Least squares means test matrices were generated for posthoc comparisons and Bonferroni's correction applied for multiple comparisons within groups. Single between group comparisons were by unpaired t-test; $\mathrm{p}<0.05$ considered significant.

\section{Results}

Four pigs died after generation of the P-V curve or within one hr of initiation of mechanical ventilation due to profound hypoxaemia and were excluded from analysis. Two pigs were excluded prior to randomisation for failure to meet blood gas criteria leaving 22 animals that completed the protocol, 11 in each group. There were no differences in body weight, volume of oleic acid infused, or dopamine dose administered between groups.

\section{Venegas Equation Curve Fitting}

All curves fit the Venegas equation with $\mathrm{R}^{2}>0.995$. The derived Venegas parameters for all animals are shown in Table 1 . In the Control group, average $\mathrm{V}_{\mathrm{T}}$ was $7.4 \pm 0.4$ $\mathrm{mL} / \mathrm{kg}$. This was higher than the $7 \mathrm{~mL} / \mathrm{kg}$ target due to increased $\mathrm{V}_{\mathrm{T}}$ in 6 of 11 animals to control $\mathrm{pH}$ following oleic acid injury as per the ARDSNet algorithm. In the 
Table I: Venegas Parameters

\begin{tabular}{|c|c|c|c|c|c|c|c|c|c|c|c|c|c|c|c|}
\hline \multicolumn{8}{|c|}{ CONTROL GROUP } & \multicolumn{8}{|c|}{ EXPERIMENTAL GROUP } \\
\hline \multicolumn{6}{|c|}{ Venegas Parameters } & \multicolumn{10}{|c|}{ Venegas Parameters } \\
\hline & $a$ & $b$ & $c$ & $d$ & $\begin{array}{l}V \text { at c- } \\
|.3| 7 d \\
(\mathrm{~mL} / \mathrm{kg})\end{array}$ & $\begin{array}{c}\mathrm{V}_{\mathrm{T}} \\
\text { delivered } \\
(\mathrm{mL} / \mathrm{kg})\end{array}$ & $\begin{array}{c}P \text { at c- } \\
\text { I.3I7d } \\
\left(\mathrm{cmH}_{2} \mathrm{O}\right)\end{array}$ & & $a$ & $b$ & $c$ & $d$ & $\begin{array}{l}V \text { at c- } \\
|.3| 7 d \\
(\mathrm{mLl} / \mathrm{kg})\end{array}$ & $\begin{array}{c}\mathrm{V}_{\mathrm{T}} \\
\text { delivered } \\
(\mathrm{mL} / \mathrm{kg})\end{array}$ & $\begin{array}{c}\mathrm{P} \text { at c- } \\
\mathrm{I} .3 \mathrm{I} / \mathrm{d} \\
\left(\mathrm{cmH}_{2} \mathrm{O}\right)\end{array}$ \\
\hline $\mathrm{I}$ & -38.6 & 1165 & 22.9 & 6.8 & 8 & 7.5 & 14 & 1 & -223.3 & 2332.3 & 35.3 & 15.8 & 10.2 & 10.1 & 14.5 \\
\hline 2 & -213.6 & 1562.9 & 28.5 & 15.3 & 4.5 & 8 & 8.4 & 2 & -97.9 & 1652 & 30.7 & 11.9 & 10.5 & 9.7 & 15 \\
\hline 3 & -41.8 & 1472.3 & 26.2 & 9 & 11.7 & 6.6 & 14.5 & 3 & -151.8 & 1461.8 & 25.4 & 11.3 & 7.1 & 7.1 & 10.5 \\
\hline 4 & -98.7 & 1600 & 25.8 & 7.9 & 9.6 & 7.1 & 15.4 & 4 & -116.5 & 1645.5 & 26.4 & 9.8 & 10 & 10.9 & 13.5 \\
\hline 5 & -25.1 & 1292.2 & 29.2 & 7.9 & 9.2 & 7.2 & 18.7 & 5 & -46.5 & 1303.4 & 24.1 & 6.4 & 8.2 & 7.9 & 15.7 \\
\hline 6 & -168 & 1152.3 & 27.9 & 12.1 & 3.3 & 7.7 & 12.1 & 6 & -72.1 & 1400.4 & 31.5 & 9.4 & 10.2 & 11.3 & 19.1 \\
\hline 7 & -54 & 1232.8 & 31.9 & 8.4 & 8.6 & 7.7 & 20.8 & 7 & -0.38 & 1159.6 & 31.4 & 8.1 & 9.4 & 9.8 & 20.7 \\
\hline 8 & -223.9 & 2295.2 & 34.5 & 15.4 & 10.4 & 7.5 & 14.3 & 8 & -51 & 1573.6 & 25.8 & 8.7 & 10.8 & 11 & 14.3 \\
\hline 9 & 10.8 & 1087.4 & 27.4 & 6.2 & 10.9 & 7.2 & 19.2 & 9 & -23.3 & 1319.6 & 24.5 & 6.2 & 10.2 & 10.5 & 16.3 \\
\hline 10 & -64.5 & 1837.8 & 34.4 & 10.9 & 13.5 & 7.2 & 20 & 10 & -16.6 & 1163.4 & 29.5 & 9.4 & 8.9 & 9.4 & 17.1 \\
\hline 11 & -46.7 & 1563.2 & 25.8 & 8.7 & 10.1 & 7.5 & 14.4 & 11 & -62.2 & 1015.2 & 31.1 & 7.8 & 6.1 & 6.6 & 20.9 \\
\hline MEAN & -87.6 & 1478.3 & 28.6 & 9.9 & 9.1 & 7.4 & 15.6 & MEAN & -78.3 & 1457.0 & 28.7 & 9.5 & 9.2 & 9.5 & 16.1 \\
\hline SD & 79.0 & 357.5 & 3.7 & 3.2 & 3.0 & 0.4 & 3.7 & SD & 65.7 & 356.2 & 3.6 & 2.7 & 1.5 & 1.6 & 3.2 \\
\hline
\end{tabular}

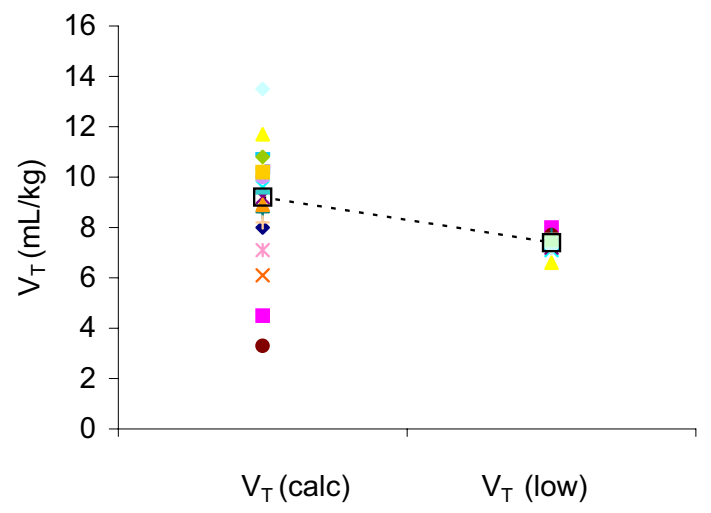

Figure 2

Mathematically Calculated versus Algorithm Low Tidal Volume. $V_{T}$ calculated from the point of maximal compliance change $(c-1.317 d)$ on the $P-V$ curve for all animals (left hand points) as compared to Control group (ARD$\mathrm{SNet}$ algorithm) low $\mathrm{V}_{\mathrm{T}}$ (right hand points). Mean $\mathrm{V}_{\mathrm{T}}$ of each group given by large open square, connected by the dotted line.

Experimental group average $\mathrm{V}_{\mathrm{T}}$, optimised to the point of maximal compliance change, was $9.5 \pm 1.6 \mathrm{~mL} / \mathrm{kg}$, signif- icantly higher than in the Control group ( $<0.05)$. In the Experimental group, the average 95\% margin of error for the target $\mathrm{V}_{\mathrm{T}}$ was $1.06 \mathrm{~mL} / \mathrm{kg}$. Of the 11 animals in this group, 10 had $\mathrm{V}_{\mathrm{T}}$ values higher than the ARDSNet protocol, and 9 of the associated $95 \%$ confidence intervals did not contain $7.0 \mathrm{~mL} / \mathrm{kg}$. One animal had a target $\mathrm{V}_{\mathrm{T}}$ below $7.0 \mathrm{~mL} / \mathrm{kg}$, although the associated confidence interval contained $7.0 \mathrm{~mL} / \mathrm{kg}$. Combining all 22 animals as one group, values for $\mathrm{V}_{\mathrm{T}}$ calculated from the Venegas equation at $P=c-1.317 d$ or $V=a+0.211 b$ varied from a low of 3.3 $\mathrm{mL} / \mathrm{kg}$ to a high of $13.5 \mathrm{~mL} / \mathrm{kg}$ (Figure 2). This targeted $\mathrm{V}_{\mathrm{T}}$ was greater than $7 \mathrm{~mL} / \mathrm{kg}$ in 18/22 animals. In the Experimental group alone, the range of individualized $\mathrm{V}_{\mathrm{T}} \mathrm{s}$ was $6.6-10.8 \mathrm{~mL} / \mathrm{kg}$. The corresponding Paw at the point $c$ $1.317 d$ for each animal is also shown in Table 1 . The range of Paw at this point showed substantial inter-animal variability ranging from 8.4 to $20.8 \mathrm{~cm} \mathrm{H}_{2} \mathrm{O}$, with a mean of $15.9 \pm 3.4 \mathrm{~cm} \mathrm{H}_{2} \mathrm{O}$ overall.

A representative P-V curve is shown in Figure 3, corresponding to animal 9 in the Experimental group. For this animal, the estimated parameters in the Venegas model were given by $a=-23.3 \mathrm{~mL}, b=1319.6 \mathrm{~mL}, c=24.5 \mathrm{~cm}$ $\mathrm{H}_{2} \mathrm{O}$, and $d=6.2 \mathrm{~cm} \mathrm{H}_{2} \mathrm{O}$. The data were collected over a wide range of pressures and volumes, and the model provided a good fit to the data $\left(\mathrm{R}^{2}=0.996\right)$. The mean volume at the point of maximal compliance change was estimated to be $\mathrm{V}_{\mathrm{T}}=(a+0.211 b) / \mathrm{w}=10.2 \mathrm{~mL} / \mathrm{kg}$, (weight $=25 \mathrm{~kg}$ ). The associated $95 \%$ margin of error was 0.54 $\mathrm{mL} / \mathrm{kg}$, derived from the estimated variance-covariance matrix for the calculated parameters. Thus the $95 \%$ confi- 


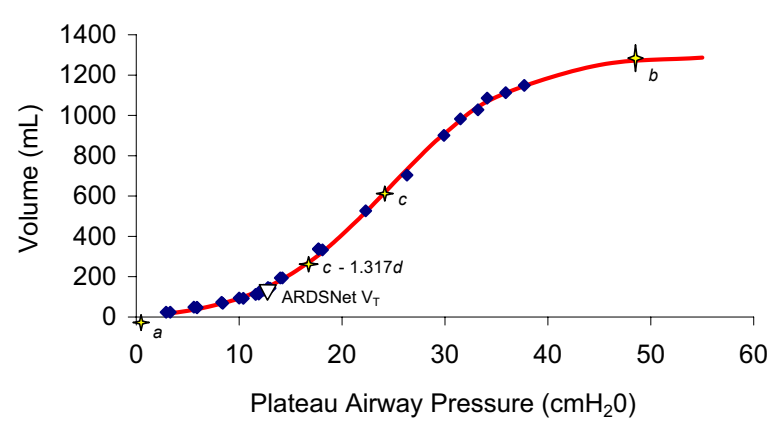

Figure 3

Representative Pressure-Volume Curve Fit to the Venegas Equation. Representative P-V curve generated at zero end expiratory pressure in a single animal in the Experimental group. Dots are individual data points. The line represents the Venegas equation derived P-V curve. The Venegas parameters $a, c$ and $b$ are labelled, as well as the volume at the point of maximal compliance change $(P=c-1.317 d)$ and the volume equivalent to $7 \mathrm{~mL} / \mathrm{kg}$ in this animal. See text for further explanation.

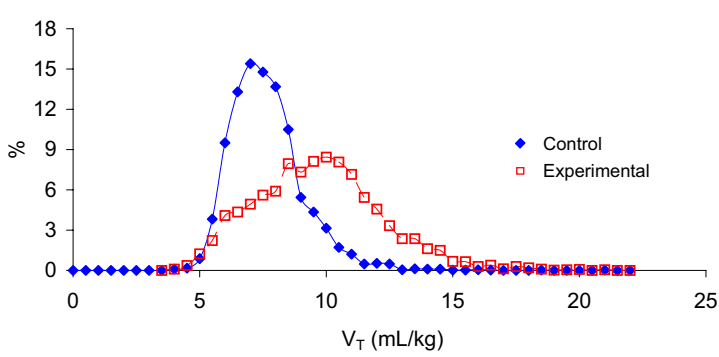

\section{Figure 4}

Frequency Distribution Curves for Tidal Volume for the Two Groups. Frequency distribution curves of $V_{T}$ for each group calculated in bins of $0.5 \mathrm{~mL} / \mathrm{kg}$. The $\mathrm{V}_{\mathrm{T}}$ bins are represented on the $x$-axis and the percentage of all $V_{T} s$ from each group in each bin is represented on the $y$-axis. Control $=$ solid diamonds. Experimental $=$ open squares.

dence interval for this volume was 9.7 to $10.8 \mathrm{~mL} / \mathrm{kg}$, which, in this example, does not encompass the $7.0 \mathrm{~mL} /$ $\mathrm{kg} \mathrm{V}_{\mathrm{T}}$ of the Control group.

\section{Variability Frequency Distribution}

The variability file for BVV introduced a coefficient of variation in $\mathrm{V}_{\mathrm{T}}$ of $15 \%$. This translated into overall fluctuations in $\mathrm{V}_{\mathrm{T}}$ between $4.1-11.1 \mathrm{~mL} / \mathrm{kg}$ in the Control group and $3.4-16.8 \mathrm{~mL} / \mathrm{kg}$ in the Experimental group. Figure 4 shows the frequency distribution of $\mathrm{V}_{\mathrm{T}} \mathrm{s}$ for each group calculated in bins of $0.5 \mathrm{~mL} / \mathrm{kg}$. A broader distribution was present in the Experimental group due to the greater range of initial centring $\mathrm{V}_{\mathrm{T}} \mathrm{s}(6.6-11.3 \mathrm{~mL} / \mathrm{kg}$ vs. $6.6-8 \mathrm{~mL} / \mathrm{kg})$ but it is evident that the addition of a variable ventilation pattern to both groups results in substantial $\mathrm{V}_{\mathrm{T}}$ overlap between groups.

\section{Minute Ventilation and Airway Pressures}

Equivalent minute ventilation was maintained in both groups at all times. This required a statistically significant increase in $f$ to $30 \pm 5 \mathrm{bpm}$ in the Control group compared to $25 \pm 6 \mathrm{bpm}(\mathrm{p}<0.05)$ in the Experimental group from hr 1 to hr 5 (Figure 5). Peak and mean Paw increased to a similar extent after oleic acid infusion in both groups. Peak Paw was modestly, but not significantly, higher in the Experimental group compared to Control (25.0 and $25.9 \mathrm{~cm} \mathrm{H}_{2} \mathrm{O}$ at 1 and 5 hrs respectively vs. 23.2 and 22.2 $\mathrm{cm} \mathrm{H}_{2} \mathrm{O}$ at analogous time periods in Control) (Figure 6). Mean Paw was approximately $7.5 \mathrm{~cm} \mathrm{H}_{2} \mathrm{O}$ at baseline and increased to $12.5 \mathrm{~cm} \mathrm{H}_{2} \mathrm{O}$ after oleic acid, not different between groups at any time-period.

In each animal, plateau pressure was determined by clamping the expiratory line for $12-18$ individual breaths over the five hr period. Using this technique, plateau pressures were well within the "safe" range of $<30 \mathrm{~cm}$ $\mathrm{H}_{2} \mathrm{O}$ in both groups: $22.3 \pm 3.7$ vs. $24.5 \pm 4.7 \mathrm{~cm} \mathrm{H}_{2} \mathrm{O}$ in the Control and Experimental groups respectively. Even mean peak airway pressures were below this theoretical upper limit (Figure 6). As well, plateau pressures were below the calculated value for the true inflection point $c$ (mean value $28.6 \pm 3.7 \mathrm{~cm} \mathrm{H}_{2} \mathrm{O}$ and $28.7 \pm 3.6 \mathrm{~cm} \mathrm{H}_{2} \mathrm{O}$ in the Control and Experimental groups respectively), except for a single measurement in each 376-breath cycle of the program file (see Figure 1 for demonstration of the largest $\mathrm{V}_{\mathrm{T}}$ ).

\section{Respiratory Gases and Mechanics}

Data are shown in Table 2. Similar changes in arterial blood gases occurred with oleic acid administration in each group. $\mathrm{PaO}_{2}$ decreased from approximately 250 $\mathrm{mmHg}$ to approximately $100 \mathrm{mmHg}$ with oleic acid infusion in both groups, then it increased over 5 hrs to a mean of greater than $150 \mathrm{mmHg}$ with no differences between groups. Following oleic acid injury, the $\mathrm{PaCO}_{2}$ increased significantly in both groups and remained elevated with no between group differences. Mixed venous $\mathrm{O}_{2}\left(\mathrm{PvO}_{2}\right)$ decreased with oleic acid injury and remained depressed over the duration of the experiment in both groups. Arte- 


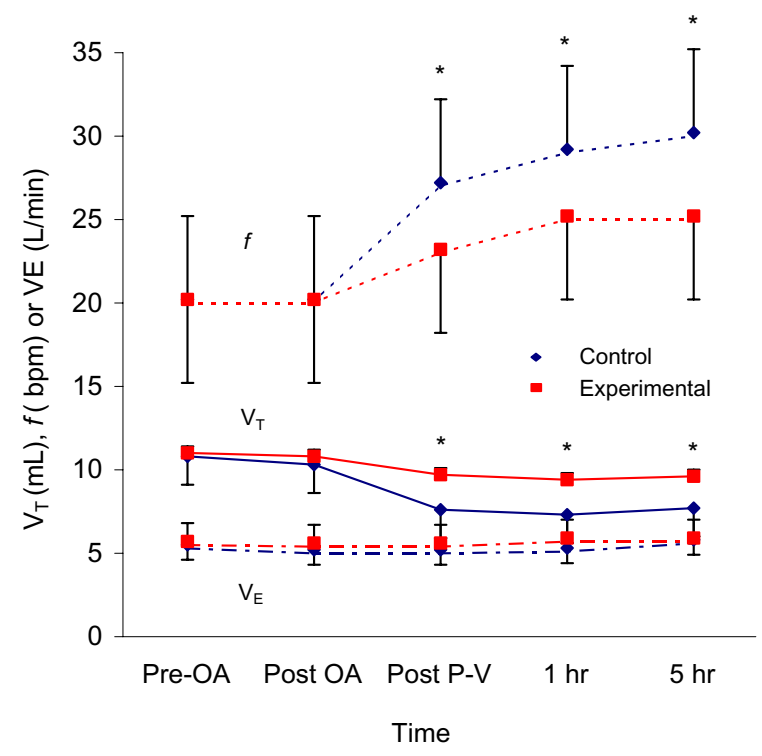

Figure 5

Ventilation Parameter for the Control and Experimental Groups. Mean values of $\mathrm{V}_{\mathrm{T}}, f$, and minute ventilation $\left(V_{E}\right)$ for Control (diamond symbol) and Experimental groups (square symbol) at each time period. Bars represent standard deviation. ${ }^{*} p<0.05$ between groups at specified time periods.

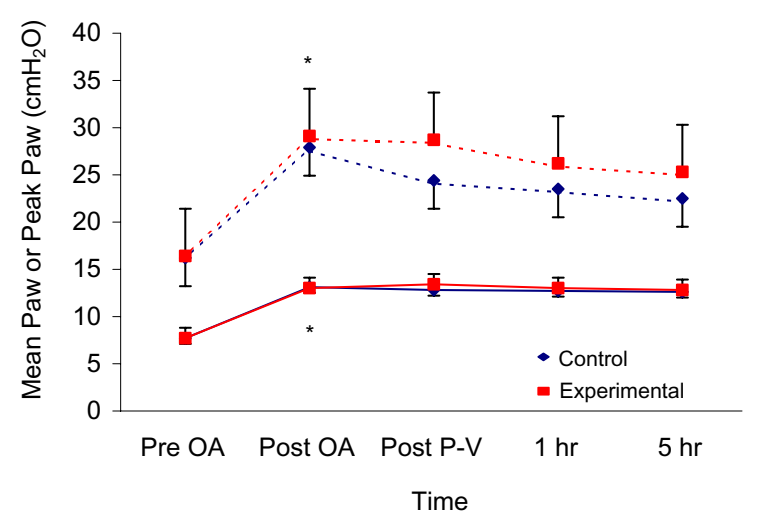

\section{Figure 6}

Mean Peak and Mean Airway Pressure for the Two Groups. Mean values for peak and mean Paw for Control (diamond) and Experimental (square) groups at each time period. Bars represent standard deviation. ${ }^{*} p<0.05$ following oleic acid. rial $\mathrm{pH}$ fell from 7.4 at control to 7.3 after P-V curve determination in both groups, associated with the respiratory acidosis. After $1 \mathrm{hr}$ of ventilation, with adjustments in $f$ and $\mathrm{V}_{\mathrm{T}}, \mathrm{PaCO}_{2}$ showed evidence of normalisation and $\mathrm{pH}$ improved in both groups for the duration of the study. Respiratory system compliance (Crs) decreased significantly with oleic acid administration and decreased further after P-V curve analysis, with no difference between groups and no group $\times$ time interaction.

\section{Haemodynamic Data}

Results are shown in Table 3. Mean arterial pressure (MAP) did not differ between groups at any time period. With P-V curve generation, mean pulmonary artery pressure (MPAP) increased over baseline but returned towards baseline values at end experiment in both groups. Pulmonary artery occlusion pressure (PAOP) did not differ between groups at any time-period. Pulmonary vascular resistance (PVR) essentially tripled with oleic acid injury and following generation of the P-V curve with some return towards normal over time in both groups. Cardiac output (CO) decreased significantly with oleic acid injury and remained depressed in both groups for the duration of the experiment.

\section{Bronchoalveolar Fluid Inflammatory Mediators}

The average concentration of IL-8 in tracheal aspirate was $5510 \pm 2540 \mathrm{pg} / \mathrm{mL}$ in the Control group versus $6500 \pm$ $2440 \mathrm{pg} / \mathrm{mL}$ in the Experimental group, not different between groups by unpaired $\mathrm{t}$-test $(\mathrm{t}$ statistic $=-0.866, \mathrm{p}=$ $0.397)$.

\section{Discussion}

With BVV, when "mathematically optimising" $\mathrm{V}_{\mathrm{T}}$ to the point of maximal compliance change on the convex portion of the P-V curve, no statistical improvement over the ARDSNet algorithm for $\mathrm{V}_{\mathrm{T}}$ selection was seen for oxygenation, respiratory mechanics or inflammatory cytokines in this animal model of ARDS. With either approach, acceptable gas exchange was maintained over 5 hrs and no significant differences in ventilating pressures, respiratory mechanics, dead space, shunt fraction or IL-8 cytokine levels were seen. We did not include a group with low $\mathrm{V}_{\mathrm{T}}$ in control mode as a previous study demonstrated significant advantages with BVV, both using the ARDSNet protocol [12]. Four mechanisms have been invoked to account for these advantages: i) stochastic resonance (noise enhancement of an input signal) [13], ii) Jensen's inequality [6], iii) increased surfactant [14] and iv) enhanced respiratory sinus arrhythmia[9]. The goal of the present study was therefore, not to examine BVV mechanistically, but to determine if the benefits seen previously with BVV could be optimised based on fitting the Venegas equation to individual P-V curves and then determining 
Table 2: Respiratory Gases and Mechanics

\begin{tabular}{|c|c|c|c|c|c|}
\hline & Pre OA & Post OA & Post PV Curve & $\mathrm{l} \mathrm{hr}$ & $5 \mathrm{hr}$ \\
\hline \multicolumn{6}{|l|}{$\mathrm{PaO}_{2}$} \\
\hline Control Group & $265 \pm 23 *$ & $101 \pm 15$ & $113 \pm 9$ & $147 \pm 46 *$ & $176 \pm 36 *$ \\
\hline Experimental Group & $267 \pm 19 *$ & $89 \pm 16$ & $100 \pm 45$ & $139 \pm 59 *$ & $163 \pm 62 *$ \\
\hline \multicolumn{6}{|l|}{$\mathrm{PaCO}_{2}$} \\
\hline Control Group & $38 \pm 4 *$ & $48 \pm 5$ & $56 \pm 9$ & $57 \pm 7$ & $51 \pm 5$ \\
\hline Experimental Group & $38 \pm 2 *$ & $48 \pm 7$ & $53 \pm 10$ & $54 \pm 21$ & $49 \pm 12$ \\
\hline \multicolumn{6}{|l|}{$\mathrm{PvO}_{2}$} \\
\hline Control Group & $43 \pm 4 *$ & $35 \pm 3$ & $38 \pm 2$ & $37 \pm 5$ & $35 \pm 4$ \\
\hline Experimental Group & $48 \pm 5 *$ & $38 \pm 5$ & $37 \pm 5$ & $39 \pm 7$ & $36 \pm 6$ \\
\hline \multicolumn{6}{|l|}{$\mathrm{pHa}$} \\
\hline Control Group & $7.45 \pm 0.04 *$ & $7.34 \pm 0.04$ & $7.30 \pm 0.07$ & $7.29 \pm 0.06$ & $7.35 \pm 0.04$ \\
\hline Experimental Group & $7.45 \pm 0.03 *$ & $7.33 \pm 0.04$ & $7.30 \pm 0.08$ & $7.30 \pm 0.08$ & $7.35 \pm 0.07$ \\
\hline \multicolumn{6}{|l|}{ Crs } \\
\hline Control Group & $1.15 \pm 0.17 *$ & $0.66 \pm 0.12$ & $0.58 \pm 0.12$ & $0.55 \pm 0.13$ & $0.61 \pm 0.11$ \\
\hline Experimental Group & $1.11 \pm 0.17 *$ & $0.70 \pm 0.22$ & $0.58 \pm 0.17$ & $0.60 \pm 0.16$ & $0.68 \pm 0.18$ \\
\hline
\end{tabular}

$\mathrm{PaO}_{2}=$ Arterial Partial Pressure $\mathrm{O}_{2}(\mathrm{mmHg})$

$\mathrm{PaCO}_{2}=$ Arterial Partial Pressure $\mathrm{CO}_{2}(\mathrm{mmHg})$

$\mathrm{PvO}_{2}=$ Mixed Venous Partial Pressure $\mathrm{O}_{2}(\mathrm{mmHg})$

$\mathrm{pHa}=$ Arterial $\mathrm{pH}$

Crs $=$ Compliance $\mathrm{L} / \mathrm{cmH}_{2} \mathrm{O}$

$* p<.05$ Within Groups vs Post PV Curve

Control Group $n=11$ Mean \pm SD

Experimental Group $n=1$ I Mean \pm SD

the ideal point on the convex portion of the curve about which to ventilate.

Using the "mathematically optimised" approach yielded mean $\mathrm{V}_{\mathrm{T}} \mathrm{s}$ that were higher than the ARDSNet algorithm (see Figure 2). The majority of calculated $\mathrm{V}_{\mathrm{T}} \mathrm{s}$ were between 8 and $10 \mathrm{ml} / \mathrm{kg}$, and both Control and Experimental $\mathrm{V}_{\mathrm{T}} \mathrm{s}$ were within the convexity of their individualised P-V curves. By ventilating with BVV in both groups, which introduced a coefficient of variation in $V_{T}$ of $15 \%$, a substantial overlap of delivered $V_{T}$ was seen apparent in the frequency distributions of $\mathrm{V}_{\mathrm{T}}$ (see Figure 4 ). We could not know a priori what $V_{\mathrm{T}}$ calculated at the point $P=c-1.317 d$ or $V=a+0.211 b$ would be relative to Control $\mathrm{V}_{\mathrm{T}}$ but their proximity, coupled with the extensive overlap due to the addition of BVV, contributed to the lack of discernable difference between groups.

The average "mathematically optimised" $\mathrm{V}_{\mathrm{T}}$ is marginally higher than that currently recommended by proponents of low $V_{T}$ ventilation. However, this $V_{T}$ is within the range chosen by most intensive care units managing ARDS patients worldwide [15] as well as the $\mathrm{V}_{\mathrm{T}}$ selected for the control arm of the three clinical trials showing no benefit from $\mathrm{V}_{\mathrm{T}}$ reduction (Control $\mathrm{V}_{\mathrm{T}}=10.8,10.3$ and $10.2 \mathrm{~mL}$ / $\mathrm{kg}$ ) [16-18]. The highest derived $\mathrm{V}_{\mathrm{T}}$ from Venegas curve fitting $(13.5 \mathrm{ml} / \mathrm{kg})$ approached what some clinicians may consider unsafe in ARDS patients using conventional ventilation [19]. However, use of higher $\mathrm{V}_{\mathrm{T}} \mathrm{s}$ in combination with BVV did not significantly increase airway pressures or IL-8 concentrations compared to Control and minute ventilation could be maintained at lower $f$. Lower $f$ may ameliorate gas trapping that has been demonstrated in ARDS patients ventilated at $f$ greater than $30 \mathrm{bpm}$ [20]. Although unable to demonstrate an advantage by "mathematically optimising" $\mathrm{V}_{\mathrm{T}}$ in the Experimental group, knowledge of the point of maximal compliance in combination with BVV may provide greater flexibility in choosing ventilator settings in individual patients, permitting a higher $\mathrm{V}_{\mathrm{T}} /$ lower $f$ combination while maintaining acceptable airway pressures.

Noisy ventilation can demonstrate Jensen's inequality in two ways. Experiments have shown that with BVV, expected mean $\mathrm{V}_{\mathrm{T}}$ is greater at the same mean Paw [21] or, conversely, that expected Paw is lower at the same mean $\mathrm{V}_{\mathrm{T}}[12]$. That is, the noise can be introduced in either pressure or volume. In the latter case, the concavity of the inverse function 
Table 3: Haemodynamic Data

\begin{tabular}{|c|c|c|c|c|c|}
\hline & Pre OA & Post OA & Post PV Curve & $\mathrm{I} \mathrm{hr}$ & $5 \mathrm{hr}$ \\
\hline \multicolumn{6}{|l|}{ MAP } \\
\hline Control Group & $108 \pm 17$ & $101 \pm 11$ & $111 \pm 19$ & $114 \pm 21$ & $99 \pm 29$ \\
\hline Experimental Group & $119 \pm 15$ & $108 \pm 25$ & $122 \pm 27$ & $122 \pm 25$ & $104 \pm 24$ \\
\hline \multicolumn{6}{|l|}{ MPAP } \\
\hline Control Group & $24 \pm 9 *$ & $35 \pm 6$ & $36 \pm 8$ & $32 \pm 5$ & $28 \pm 3 *$ \\
\hline Experimental Group & $23 \pm 5 *$ & $35 \pm 6$ & $34 \pm 7$ & $33 \pm 7$ & $29 \pm 7 *$ \\
\hline \multicolumn{6}{|l|}{ PAOP } \\
\hline Control Group & $9.3 \pm 1.5$ & $10.5 \pm 1.9$ & $9.9 \pm 1.1$ & $9.9 \pm 1.3$ & $9.6 \pm 1.5$ \\
\hline Experimental Group & $10.0 \pm 1.7$ & $10.6 \pm 1.4$ & $11.0 \pm 1.5$ & $10.8 \pm 1.5$ & $11.1 \pm 1.5$ \\
\hline \multicolumn{6}{|l|}{ PVR } \\
\hline Control Group & $4.3 \pm 2.6 *$ & $\mid \mathrm{I} .1 \pm 4.0$ & $12.4 \pm 6.0$ & $12.3 \pm 4.6$ & $8.5 \pm 2.8 *$ \\
\hline Experimental Group & $3.2 \pm 1.5 *$ & $8.6 \pm 2.0$ & $8.8 \pm 3.0$ & $9.8 \pm 3.1$ & $7.6 \pm 3.0 *$ \\
\hline \multicolumn{6}{|l|}{$\mathrm{CO}$} \\
\hline Control Group & $3.5 \pm 0.7 *$ & $2.3 \pm 0.5$ & $2.3 \pm 0.6$ & $2.0 \pm 0.5$ & $2.2 \pm 0.6$ \\
\hline Experimental Group & $4.2 \pm 0.8 *$ & $2.9 \pm 0.5$ & $2.8 \pm 0.6$ & $2.5 \pm 0.5$ & $2.4 \pm 0.5$ \\
\hline
\end{tabular}

MAP = Mean Arterial Pressure $(\mathrm{mmHg})$

MPAP = Mean Pulmonary Arterial Pressure $(\mathrm{mmHg})$

$\mathrm{PAOP}=$ Pulmonary Artery Occlusion Pressure $(\mathrm{mmHg})$

$\mathrm{PVR}=$ Pulmonary Vascular Resistance $\left(\mathrm{mmHg} \cdot \mathrm{L} \cdot \mathrm{min}^{-1}\right)$

$\mathrm{CO}=$ Cardiac Output (L/min)

$* \mathrm{p}<.05$ Within Groups vs Post PV Curve

Control Group $n=11$ Mean \pm SD

Experimental Group $n=1 \mid$ Mean \pm S.D.

$G(V)=P=c+d^{*} \ln \left(\frac{v-a}{a+b-v}\right)$

is being exploited in the region of low volumes. Thus, a lower expected plateau pressure for a given mean $V_{T}$ with $\mathrm{BVV}$ is also a consequence of Jensen's inequality.

Current recommendations to limit ventilator induced lung injury (VILI) include a combination of low $\mathrm{V}_{\mathrm{T}}$ and adequate PEEP to maintain an open lung with plateau pressures below $30 \mathrm{~cm} \mathrm{H}_{2} \mathrm{O}$. The plateau pressures over the course of this experiment, determined by clamping the expiratory line in $12-18$ individual breaths per experiment, were well within the "safe" range in both groups: $22.3 \pm 3.7$ vs. $24.5 \pm 4.7 \mathrm{~cm} \mathrm{H}_{2} \mathrm{O}$ in the Control and Experimental groups respectively. Plateau pressures were also below the calculated value for the true inflection point $c$ on the Venegas curve (mean value $28.6 \pm 3.7 \mathrm{~cm}$ $\mathrm{H}_{2} \mathrm{O}$ and $28.7 \pm 3.6 \mathrm{~cm} \mathrm{H}_{2} \mathrm{O}$ in the Control and Experimental groups respectively). Even mean peak airway pressures were below this theoretical upper limit (Figure 6). In each experiment, a single breath exceeded point $c$ (the upper bound for the convexity of the P-V curve). The average $V_{T}$ of this single largest breath delivered once in the file of 376 breaths (Figure 1) for the Experimental group was
$426 \pm 79 \mathrm{~mL}$ associated with a peak Paw of $42 \pm 9 \mathrm{~cm} \mathrm{H}_{2} \mathrm{O}$ at PEEP $8 \mathrm{~cm} \mathrm{H}_{2} \mathrm{O}$.

Brower et al. [22] recently re-analysed the ARDSNet data by quartiles for plateau pressure and found that $\mathrm{V}_{\mathrm{T}}$ reduction was associated with reduced mortality in all patients, including those with plateau pressures less than $32 \mathrm{~cm}$ $\mathrm{H}_{2} \mathrm{O}$. These authors contend that there is no "safe" level of plateau pressure in acute lung injury and the lowest $\mathrm{V}_{\mathrm{T}}$ and plateau pressure compatible with acceptable gas exchange should be a goal. If this is borne out, then application of a variable ventilator pattern, which has consistently resulted in improved gas exchange and respiratory mechanics at airway pressures that were equivalent to or lower than those obtained during conventional ventilation, in combination with the lowest $\mathrm{V}_{\mathrm{T}}$, may be beneficial.

The risk of strict adherence to low $\mathrm{V}_{\mathrm{T}}$ with conventional ventilation is alveolar derecruitment and reduced $\mathrm{PaO}_{2}$ and $\mathrm{SaO}_{2}$. While low $\mathrm{V}_{\mathrm{T}}$ strategies have been embraced, recent work indicates that survival from ARDS may be complicated by neurocognitive decline correlated to hypoxaemic periods during mechanical ventilation $[23,24]$. Richard et al. [25] advocate recruitment manoeuvres or increasing PEEP as alternative strategies to counter- 
act low $\mathrm{V}_{\mathrm{T}}$ derecruitment. But recruitment manoeuvres did not show a sustained benefit for gas exchange in the ARDSNet trial [26] and increasing PEEP alone may be problematic. We have recently demonstrated that BVV is superior to an established recruitment manoeuvre to improve oxygenation in this animal model [8]. Martynowicz et al. [27], using parenchymal markers in an oleic acid injury model have demonstrated that PEEP restores airspace volume only at pressures that result in a universal increase in parenchymal stress. Eisner et al. [28] showed that the risk of barotrauma increased 1.67 fold for each 5$\mathrm{cm}$ increment in PEEP and Esteban et al. [15] determined that increasing PEEP was an independent factor associated with mortality during mechanical ventilation.

A recent multi-centre trial has demonstrated no difference in patient outcome for low $\left(8.3 \mathrm{~cm} \mathrm{H}_{2} \mathrm{O}\right)$ versus high $\left(13.2 \mathrm{~cm} \mathrm{H}_{2} \mathrm{O}\right.$ ) levels of PEEP $[29,30]$. Since PEEP greater than $8 \mathrm{~cm} \mathrm{H}_{2 \mathrm{O}}$ is not beneficial to outcome, application of a variable signal to the ventilatory pattern with $\mathrm{BVV}$ may provide an alternative approach, producing net recruitment of previously fluid filled or atelectatic units without the potentially harmful effects of either increasing PEEP or the use of prolonged recruitment manoeuvres that deliver high levels of distending stress. Additionally, variable ventilation promotes release of endogenous surfactant, offering another mechanism for improvement in alveolar stability [14].

Potential criticisms of the present study include the use of PEEP and the use of a static P-V curve analysis for a dynamic application. Eight $\mathrm{cm} \mathrm{H}_{2} \mathrm{O}$ PEEP was applied to both groups and resulted in peak airway pressures that exceeded the point of maximal compliance change for greater than $90 \%$ of breaths even in the Control group. The major consequence of this degree of PEEP is an upward shift of the P-V curve derived at zero end expiratory pressure (ZEEP) such that total volume would be greater at any point below $c$. However, in the models proposed by Hickling, this level of PEEP is associated with maintained convexity at lower $\mathrm{V}_{\mathrm{T}}$ and as such, has no effect on the interpretation of the results with regards to Jensen's inequality. We chose this level of PEEP to more closely approximate clinical practice, to provide evidence of a consistent lesion between animals with oleic acid administration and to ensure acceptable levels of gas exchange with the lower $\mathrm{V}_{\mathrm{T}}$ strategy. Initial attempts to analyse the P-V relationship on PEEP gave unreliable values for the point $P=c-1.317 d$ in our hands; a consequence of inadequate definition of the lower asymptote in these earlier experiments.

We recognize that application of $\mathrm{V}_{\mathrm{T}}$ values obtained under "quasi" static conditions may not be directly applicable to the dynamic breathing cycle due to a shift to the right that occurs with increasing inspiratory flows and the increase in volume that may occur at the beginning of the dynamic inspirations due to recruitment from tidal volume independent of PEEP [31]. As such, our Experimental $V_{T}$ settings should be considered a first attempt to utilise information obtained from $\mathrm{P}-\mathrm{V}$ curves to individualise BVV settings and may have also contributed to the lack of difference seen. However, a rightward shift of the curve implies that Jensen's inequality may apply over an even broader $\mathrm{V}_{\mathrm{T}}$ range provided that a convex P-V relationship is maintained. Examination of dynamic P-V loops from Rimensberger et al. [32] indicate that convexity persists. In addition, further analysis of the Venegas equation reveals its derivative closely resembles a Gaussian distribution [3]. Thus the probability density function of this equation indicates the likelihood of alveolar recruitment at a given airway pressure and the equation itself could be deemed the cumulative distribution function for alveolar recruitment. Airway opening leading to alveolar recruitment is curvilinear [13]. Under such circumstances Jensen's inequality implies that a noisy mean driving pressure could augment recruitment.

In an oleic acid lung injury model, Wilson and colleagues [33] suggested that oedematous lung did not open and close, but that alveoli changed from fluid-filled units to air-filled units with the P-V curve strongly sigmoidal. Following lung injury, at 3-5 $\mathrm{cm} \mathrm{H}_{2} \mathrm{O}$ PEEP, convex curvature was seen in $\mathrm{P}-\mathrm{V}$ curves over the range of inflation pressures seen in our study. They examined P-V curves for regional lung volumes of 1-2 mL, using the parenchymal marker technique. Thus in a similar model to ours, convexity was demonstrated for small regional lung volumes, suggesting applicability of Jensen's inequality with an oleic acid lung injury model of ARDS in the presence of PEEP. These authors further developed a mathematical model based on their findings. Until airway pressure exceeded $8 \mathrm{~cm}$ $\mathrm{H}_{2} \mathrm{O}$ (the level of PEEP in our study), the duct to the fluidfilled alveolus was assumed blocked by a liquid bridge. Above this pressure, the P-V curve was convex as the air bubble penetrated the mouth of the alveolus for various degrees of fluid filling. When the alveolus remained fluidfilled, the lung compliance was low. An abrupt change occurred as the air bubble entered the alveolus. At this transition, compliance rapidly increased with no change in alveolar tissue volume. Based on this modeling, when the lung is oedematous, noise added to the mean airway pressure signal will increase the likelihood of inducing the abrupt change in compliance, seen with entry of air bubbles into alveoli, a situation that would result in improved gas exchange.

The lack of difference between groups suggests that determination of a "mathematically optimal " $\mathrm{V}_{\mathrm{T}}$ may be clinically irrelevant during BVV, provided that ventilation is 
occurring on the convex portion of the P-V curve. Adhering to the ARDSNet algorithm in this study assured that ventilation occurred on the convex portion of the curve in all animals. Knowing this may be advantageous due to the difficulties applying static curves to dynamic conditions listed above. Moreover, rigorous definition of the P-V relationship requires a finite time off the ventilator, can be difficult to analyse clinically, and imposes a potential risk for instability in gas exchange and mechanics during the manoeuvre. $\mathrm{PaO}_{2}$ and compliance decreased in 18 of 22 animals immediately following P-V curve determination in the present study, providing credence to the above concerns. However, the results of the present study suggest that when ventilating with BVV, knowledge of the point of maximal compliance change on the convex portion of the $\mathrm{P}-\mathrm{V}$ curve relative to $\mathrm{V}_{\mathrm{T}}$ determined using the ARDSNet algorithm might permit adjustments in $\mathrm{V}_{\mathrm{T}}$ in selected patients without the risk of excessive airway pressures. Finally, Jensen's inequality can be generalised and as such defining a simpler equation for the convex interval of the $\mathrm{P}-\mathrm{V}$ curve under low $\mathrm{V}_{\mathrm{T}}$ conditions is possible.

We chose to examine only intratracheal IL-8 levels as a marker of inflammatory changes in the present study as previous work in our laboratory did not demonstrate measurable effects on tumour necrosis factor $\alpha$, IL- 6 or IL10 in this porcine oleic acid model [11]. The high level of tracheal fluid IL-8 measured in both groups is comparable to our previous results. Similar cytokine levels for the two ventilatory approaches suggest that the inflammatory injury was comparable.

\section{Conclusion}

In this porcine model of acute lung injury, "mathematically optimised" P-V curve fitting to calculate the mean $\mathrm{V}_{\mathrm{T}} / \mathrm{kg}$ about which to centre variable ventilation yielded a broad range for this calculated volume. Although not clearly advantageous over the standard approach - low $V_{T}$ as determined by the ARDSNet algorithm - $\mathrm{V}_{\mathrm{T}}$ selected mathematically according to the point of maximal compliance change on the P-V curve, in combination with a variable pattern of ventilation, may permit some leeway in $\mathrm{V}_{\mathrm{T}}$ settings provided that airway pressures are maintained within acceptable limits. This study also indicates that the standard ARDSNet algorithm assures ventilation is occurring on the convex portion of the P-V curve with this model. Application of Jensen's inequality provides theoretical proof of why a noisy or variable ventilatory approach is advantageous under these circumstances.

\section{Competing interests}

Dr. Mutch is co-founder of Biovar Life Support Inc., which has developed the mechanical ventilator described in this paper. Worldwide exclusive rights to this ventilator have been licensed to Respironics Inc. To date no ventilators have been sold clinically. In the event of sales of this ventilator, Dr. Mutch and the University of Manitoba would stand to gain financially. None of the other authors have a financial interest in the ventilator.

\section{Authors' contributions}

M.R.G. supervised conduct of the experiments, helped analyse the data and helped write the paper. C.J.H. was responsible for conduct of the experiments as a fellow in the Anesthesia Laboratory. J.F.B. did the Jensen's inequality modelling and the statistical analysis related to the P-V curve fitting. L.G.G. helped with the experiments, data retrieval and collation and table and figure production. B.M.M. supervised the cytokine assays and their interpretation and helped write the paper. W.A.C.M. conceived the study, analysed and interpreted data and helped write the paper.

\section{Acknowledgements}

The authors thank Respironics Inc. for providing the Esprit ventilator for the study and the hardware and software development for BVV as well as financial support. The authors also thank Biovar Life Support Inc. for financial support. We thank Elizabeth Walker for carrying out the cytokine assays.

\section{References}

I. Hickling KG: The pressure-volume curve is greatly modified by recruitment. Am J Respir Crit Care Med 1998, I 58: 194-202.

2. Hickling KG: Best compliance during a decremental, but not incremental, positive end-expiratory pressure trial is related to open-lung positive end-expiratory pressure: a mathematical model of acute respiratory distress syndrome lungs. Am J Respir Crit Care Med 200I, I 63:69-78.

3. Venegas JG, Harris RS, Simon BA: A comprehensive equation for the pulmonary pressure-volume curve. J Appl Physiol 1998, 84:389-395.

4. Harris RS, Hess DR, Venegas JG: An objective analysis of the pressure-volume curve in the acute respiratory distress syndrome. Am J Respir Crit Care Med 2000, I 6 I:432-439.

5. The Acute Respiratory Distress Syndrome Network: Ventilation with lower tidal volumes as compared with traditional tidal volumes for acute lung injury and the acute respiratory distress syndrome. N Engl J Med 2000, 342: I30 I- I 308.

6. Brewster JF, Graham MR, Mutch WAC: Convexity, Jensen's inequality and benefits of noisy mechanical ventilation. $J R$ Soc Interface 2005, 2:393-6.

7. Jensen JL: Sur les functions convexes et les inégualités entre les valeurs moyennes. Acta Math 1906, 30: I75-193.

8. Funk DJ, Graham MR, Girling LG, Thliveris JA, McManus BM, Walker EK, Rector ES, Hillier C, Scott JE, Mutch WAC: A comparison of biologically variable ventilation to recruitment manoeuvres in a porcine model of acute lung injury. Respir Res 2004, 5:22.

9. Mutch WAC, Graham MR, Girling LG, Brewster JF: Fractal ventilation enhances respiratory sinus arrhythmia. Respir Res 2005, 6:41.

10. Ross S: A First Course in Probability 6th edition. Upper Saddle River, NJ, USA:Prentice Hall; 2002.

II. Mutch WAC, Lefevre GR: Health, 'small-worlds', fractals and complex networks: an emerging field. Med Sci Monit 2003, 9:MT19-MT23.

12. Boker A, Graham MR, Walley KR, McManus BM, Girling LG, Walker E, Lefevre GR, Mutch WAC: Improved arterial oxygenation with biologically variable or fractal ventilation using low tidal volumes in a porcine model of acute respiratory distress syndrome. Am J Respir Crit Care Med 2002, I 65:456-462. 
13. Suki B, Alencar AM, Sujeer MK, Lutchen KR, Collins JJ, Andrade JR. JS, Ingenito EP, Zapperi S, Stanley HE: Life-support system benefits from noise. Nature 1998, 393:127-128.

14. Arold SP, Suki B, Alencar AM, Lutchen KR, Ingenito EP: Variable ventilation induces endogenous surfactant release in normal guinea pigs. Am J Physiol Lung Cell Mol Physiol 2003, 285:L370-L375.

15. Esteban A, Anzueto A, Frutos F, Alia I, Brochard L, Stewart TE, Benito S, Epstein SK, Apezteguia C, Nightingale P, Arroliga AC, Tobin MJ: Characteristics and outcomes in adult patients receiving mechanical ventilation: a 28-day international study. JAMA 2002, 287:345-355.

16. Stewart TE, Meade MO, Cook DJ, Granton JT, Hodder RV, Lapinsky SE, Mazer CD, McLean RF, Rogovein TS, Schouten BD, Todd TRJ, Slutsky AS: Evaluation of a ventilation strategy to prevent barotrauma in patients at high risk for acute respiratory distress syndrome. N Engl J Med 1998, 338:355-36I.

17. Brochard L, Roudot-Thoraval F, Roupie E, Delclaux C, Chastre J, Fernandez-Mondejar E, Clementi E, Mancebo J, Factor P, Matamis D, Ranieri M, Blanch L, Rodi G, Mentec H, Dreyfuss D, Ferrer M, BrunBuisson C, Tobin M, Lemaire F: Tidal volume reduction for prevention of ventilator-induced lung injury in acute respiratory distress syndrome. The Multicenter Trail Group on Tidal Volume reduction in ARDS. Am J Respir Crit Care Med 1998, 158:183|-|838.

18. Brower RG, Shanholtz CB, Fessler HE, Shade DM, White PJ, Wiener CM, Teeter JG, Dodd-o JM, Almog Y, Piantadosi S: Prospective, randomized, controlled clinical trial comparing traditional versus reduced tidal volume ventilation in acute respiratory distress syndrome patients. Crit Care Med 1999, 27:1492-1498.

19. Tobin MJ: Culmination of an era in research on the acute respiratory distress syndrome. N Engl | Med 2000, 342: I360-|36I.

20. de Durante G, Del Turco M, Rustichini L, Cosimini P, Giunta F, Hudson LD, Slutsky AS, Marco Ranieri V: ARDSNet lower tidal volume ventilatory strategy may generate intrinsic positive end-expiratory pressure in patients with acute respiratory distress syndrome. Am J Respir Crit Care Med 2002, 165: I 27 I- I 274.

21. Mutch WAC, Harms S, Lefevre GR, Graham MR, Girling LG, Kowalski SE: Biologically variable ventilation increases arterial oxygenation over that seen with positive end-expiratory pressure alone in a porcine model of acute respiratory distress syndrome. Crit Care Med 2000, 28:2457-2464.

22. Brower RG, Krishnan JA, Thompson BT, et al.: Effects of tidal volume reduction $\left(V_{T}-R\right)$ in acute lung injury patients with inspiratory plateau pressures $<32 \mathbf{c m H}_{2} \mathrm{O}$ before VT-R. $A m$ Jespir Crit Care Med (supplements) 2003, 167:A6I6.

23. Hopkins RO, Weaver LK, Collingridge D, Parkinson RB, Chan KJ, Orme JF): Two-year cognitive, emotional, and quality-of-life outcomes in acute respiratory distress syndrome. Am J Respir Crit Care Med 2005, I 7 I:340-347.

24. Hopkins RO, Weaver LK, Chan KJ, Orme JFJ: Quality of life, emotional, and cognitive function following acute respiratory distress syndrome. J Int Neuropsychol Soc 2004, 10:1005-1017.

25. Richard JC, Maggiore SM, Jonson B, Mancebo J, Lemaire F, Brochard $\mathrm{L}$ : Influence of tidal volume on alveolar recruitment. Respective role of PEEP and a recruitment maneuver. Am J Respir Crit Care Med 2001, 163:1609-1613.

26. Villagra A, Ochagavia A, Vatua S, Murias G, Del Mar F, Lopez AJ, Fernandez $R$, Blanch $L$ : Recruitment maneuvers during lung protective ventilation in acute respiratory distress syndrome. $\mathrm{Am} J$ Respir Crit Care Med 2002, 165:165-170.

27. Martynowicz MA, Minor TA, Walters BJ, Hubmayr RD: Regional expansion of oleic acid-injured lungs. Am J Respir Crit Care Med 1999, 160:250-258.

28. Eisner MD, Thompson BT, Schoenfeld D, Anzueto A, Matthay MA: Airway pressures and early barotrauma in patients with acute lung injury and acute respiratory distress syndrome. Am J Respir Crit Care Med 2002, 165:978-982.

29. Brower RG, Lanken PN, Macintyre N, Matthay MA, Morris A, Ancukiewicz M, Schoenfeld D, Thompson BT: Higher versus lower positive end-expiratory pressures in patients with the acute respiratory distress syndrome. $N$ Engl J Med 2004, 35 I:327-336.

30. Levy MM: PEEP in ARDS - how much is enough? N Engl J Med 2004, 35 I:389-39I.

31. Adams AB, Cakar N, Marini JJ: Static and dynamic pressure-volume curves reflect different aspects of respiratory system mechanics in experimental acute respiratory distress syndrome. Respir Care 2001, 46:686-693.

32. Rimensberger PC, Cox PN, Frndova H, Bryan AC: The open lung during small tidal volume ventilation: concepts of recruitment and "optimal" positive end-expiratory pressure. Crit Care Med 1999, 27:1946-1952.

33. Wilson TA, Anafi RC, Hubmayr RD: Mechanics of edematous lungs. J Appl Physiol 200I, 90:2088-2093.
Publish with Biomed Central and every scientist can read your work free of charge

"BioMed Central will be the most significant development for disseminating the results of biomedical research in our lifetime. "

Sir Paul Nurse, Cancer Research UK

Your research papers will be:

- available free of charge to the entire biomedical community

- peer reviewed and published immediately upon acceptance

- cited in PubMed and archived on PubMed Central

- yours - you keep the copyright

Submit your manuscript here:

http://www.biomedcentral.com/info/publishing_adv.asp
BioMedcentral 